\title{
Building up fundamental strength to fight against COVID- I 9 for patients with chronic diseases and complications
}

\section{Introduction}

This paper describes qualitatively and quantitatively the actions to protect some patients with chronic diseases and complications during this COVID-19 period.

\section{Methods}

\section{Background}

The author is a medical research scientist in the field of both metabolism and endocrinology, concentrating in diabetes and its complications. He is also a professionally trained mathematician, physicist, and engineer. The patients in this case report include the following four individuals:

i. Patient A: male, 73-years-old, 3 chronic diseases and other 6 complications over 25 years (the author himself).

ii. Patient B: female, 72 years old, 3 chronic diseases and CVD over 22 years.

iii. Patient $\mathrm{C}$ : male, 47 years old, obese and 3 chronic diseases over 4 years

iv. patient D: female, 73 years old, 3 chronic diseases and many complications over 15 years.

The author eluded the 2003 SARS threat in China and Taiwan. In early January 2020, when the strange "Wuhan pneumonia" rumors suddenly appeared on certain Asian news networks, he immediately recognized the danger associated with this newly found virus. He then started his "self-quarantine" in the United States on 1/19/2020, much earlier than the majority of Europeans and Americans who became aware of its potential damage and severity.

Over these past 106 days, the author has maintained his personal contacts with other three patients using the internet only.

From Reference 1, COVID-19 is a disease caused by SARSCoV-2 virus which uses ACE-2 for cell entry. Currently, we thought that it is spread through respiratory droplets, though the transmission is still under investigation. Also, the virus has been found in blood and stool. Figure 1 shows that COVID-19 is a spectrum of diseases. Approximately $80 \%$ of confirmed cases are uncomplicated SARSCoV-2 infection which may lead to mild pneumonia. About $15 \%$ would lead into severe pneumonia, with the remaining 5\% ending up as acute respiratory distress syndrome (ARDS). Incidentally, this $5 \%$ percentage just falls into the range for the current death rate of COVID- 19 , which is about $4 \%$ to $10 \%$

\section{Epidemic information}

The author's first rule is that he does not trust any governments' statements regarding this virus. Most politicians are concerned more about politics, economics, or even "saving face" and not relying on scientific truths and medical facts. Of course, there are still lots of scientific facts that need to be uncovered through scientific
Volume 5 Issue 3 - 2020

\section{Gerald C Hsu}

Medical Research Scientist, eclaireMD Foundation, USA

Correspondence: Gerald C Hsu, Medical Research Scientist, eclaireMD Foundation, USA, Email g.hsu@eclairemd.com

Received: May 05, 2020 | Published: May 12, 2020

and medical professionals. As a scientist, the author believes that decisions related to human life should only be based on scientific and medical knowledge along with experiences. Therefore, he decided to conduct his own data analysis (a sample analysis shown in Figure 2). He does not need any complex equations or fancy mathematical models to analyze COVID-19, but he must look into the situation from "correct" cutting-angles or entry-points without any distorted facts. In this virus-fighting business, having correct information is our first important battlefield; otherwise, data analysis results would end up with what computer scientists consider as "garbage in leads to garbage out".

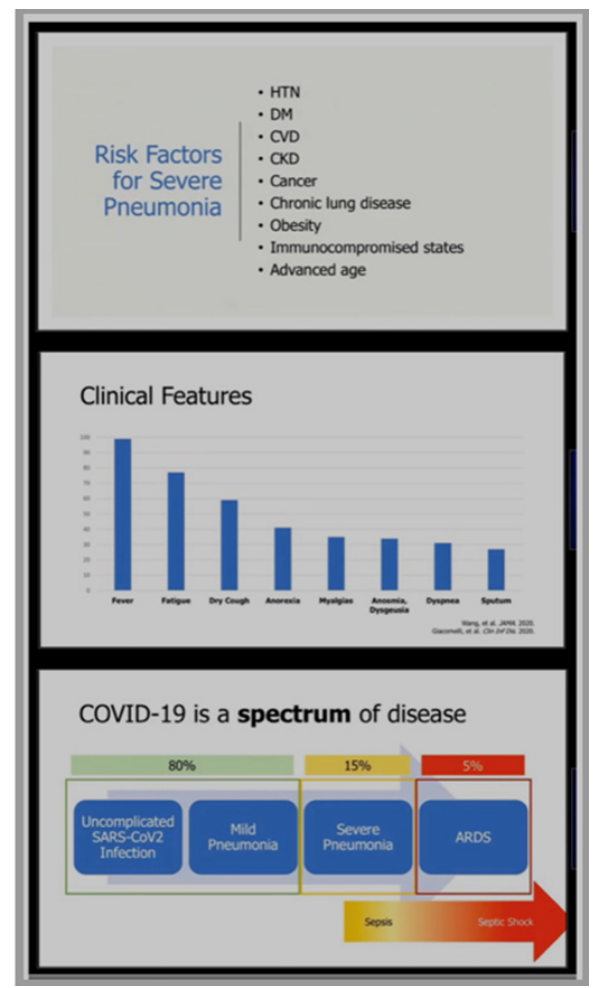

Figure I COVID-I9 information (Reference I). 
Done

covid-19.csv

\begin{tabular}{|l|l|l|l|l|l|l|}
\hline 2020-05-04 09:05 & Area & Confirmed & Confirmed $\%$ & Death & Death $\%$ & Density \\
\hline Zone 1 & Europe & $1,389,627$ & $0.1878 \%$ & 140,513 & $10.11 \%$ & 73 \\
\hline Zone 2 & US & $1,158,341$ & $0.351 \%$ & 67,686 & $5.84 \%$ & 34 \\
\hline Zone 3 & UK & 186,599 & $0.2806 \%$ & 28,446 & $15.24 \%$ & 275 \\
\hline Zone 4 & Korea/Taiwan/Singapore & 30,017 & $0.0371 \%$ & 276 & $0.92 \%$ & 591 \\
\hline Zone 5 & Australia/NZ/Canada & 67,412 & $0.1004 \%$ & 3,797 & $5.63 \%$ & 4 \\
\hline & Subtotal & $2,645,397$ & $0.2172 \%$ & 212,272 & $8.02 \%$ & \\
\hline Zone 6 & China & 84,403 & $0.0059 \%$ & 4,643 & $5.5 \%$ & 149 \\
\hline Zone 7 & Japan & 15,068 & $0.0121 \%$ & 531 & $3.52 \%$ & 336 \\
\hline Zone 8 & India & 42,533 & $0.0032 \%$ & 1,373 & $3.23 \%$ & 450 \\
\hline & WHO & $3,481,329$ & $0.0447 \%$ & 247,497 & $7.11 \%$ & 52 \\
\hline
\end{tabular}

Figure 2 The author's own partial data analysis of COVID-I9 (5/4/2020).

The spread of this disease depends mainly on the physical contact among people. Therefore, the population density is his first key factor. The combined inhabitants of China and India make up 38\% of the world's total population, and both of their data reliability and accuracy are questionable due to different reasons. This is why he chose not to look into the data provided by the World Health Organization (WHO). Furthermore, he did not look at the confirmed case "numbers", but rather focused on the confirmed case "percentages" (i.e. confirmed case number divided by population). This confirmed case percentage could offer a better and clearer picture regarding whether that particular country was hiding the truth or providing inaccurate numbers. Of course, both of the confirmed case numbers and percentages are reflecting the availability and reliability of the virus testing kits. Specifically, he discovered that certain nations hide the truth by controlling the data "influx" for example, by reducing the number of confirmed cases through different layers of government bureaucracy, reporting an inaccurate number, or refusing additional tests to be performed on the population. However, most underdeveloped or some developing nations, they are indeed in a situation of short supply of virus test kits.

Ironically, he discovered that the death percentages among different nations (death number divided by confirmed number) were quite consistent from each other, in a range between $4 \%$ to $10 \%$. This death rate usually reflects that particular country's healthcare conditions and medical resources in terms of their facility availability and expertise level. Another non-related issue regarding the death rate is the "Iwo Jima" campaigns of the Pacific War had a $6.2 \%$ death rate over 36 days of battles (6,800 out of 110,000 soldiers).

\section{Chronic diseases}

Specifically, for seniors over the age of 70 , who have existing chronic diseases or history of complications, their death probability due to COVID-19 is much higher than younger, healthier people (Figure 3). This category applies to Patients A, B, C (middle-age with obesity and diabetes), and $\mathrm{D}$.

As indicated in Reference 2 titled, "Linkage among metabolism, immune system, and various diseases using GH-Method: mathphysical medicine (MPM)", the most effective defense of COVID-19 is our immunity. Furthermore, our immune system is closely related to our overall metabolic conditions. In order to strengthen our metabolism, we must manage our daily lifestyle well over a long period of time in order to build up a strong and firm foundation for our health (Figure 4).

In short, lifestyle is similar to arsenal capacity based on educational, technological, and industrial power, whereas metabolism is similar to the effectiveness or destruction power of the weapons available to the soldiers. Immunity is similar to the strength of the defensive armed forces, while diseases (chronic, cancer, and infectious) are similar to an enemy's invasion force. Lastly, death is similar to the outcomes of a war (death rates).

The author's research specialty is in the area of metabolic disorders. In this article, he will summarize his knowledge and experiences in a quantitative manner, specifically related to COVID-19 (Figure 5) (Figure 6). 


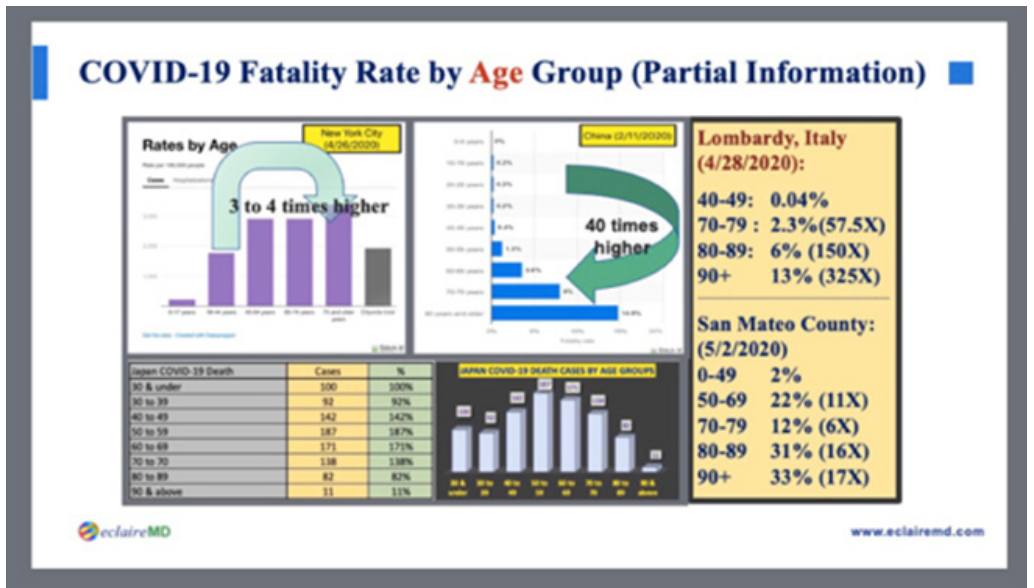

Figure 3 Mortality of COVID-19 by age group.

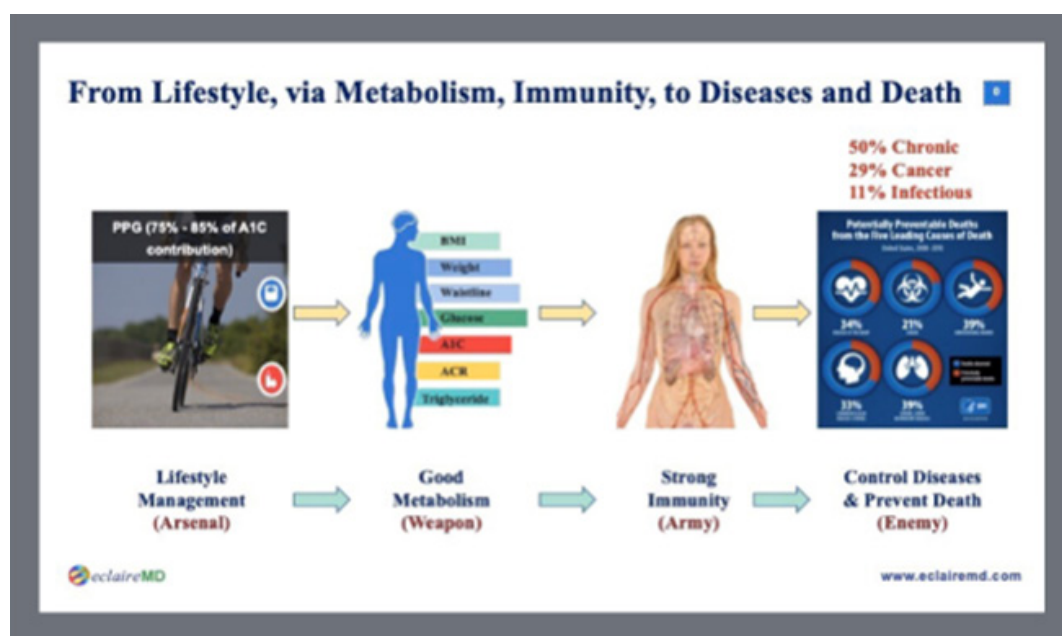

Figure 4 Relationships among lifestyle, metabolism, immunity, and diseases.

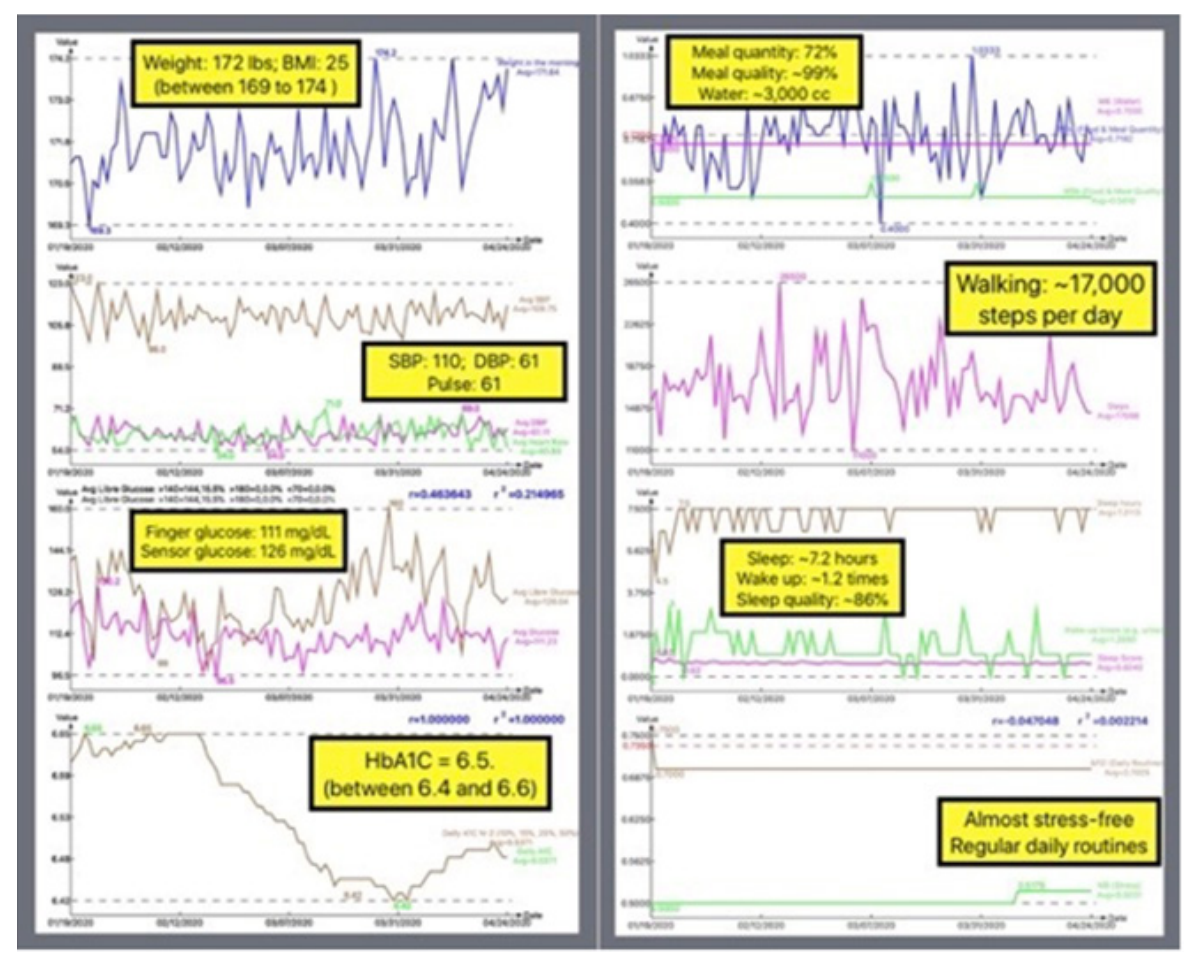

Figure 5 Metabolism outputs (MI through M4) and inputs (M5 through MI0) during COVID-I9.

Citation: Hsu GC. Building up fundamental strength to fight against COVID- 9 for patients with chronic diseases and complications. MOJ Gerontol Ger. 2020;5(3):76-80. DOI: 10.15406/mojgg.2020.05.00234 


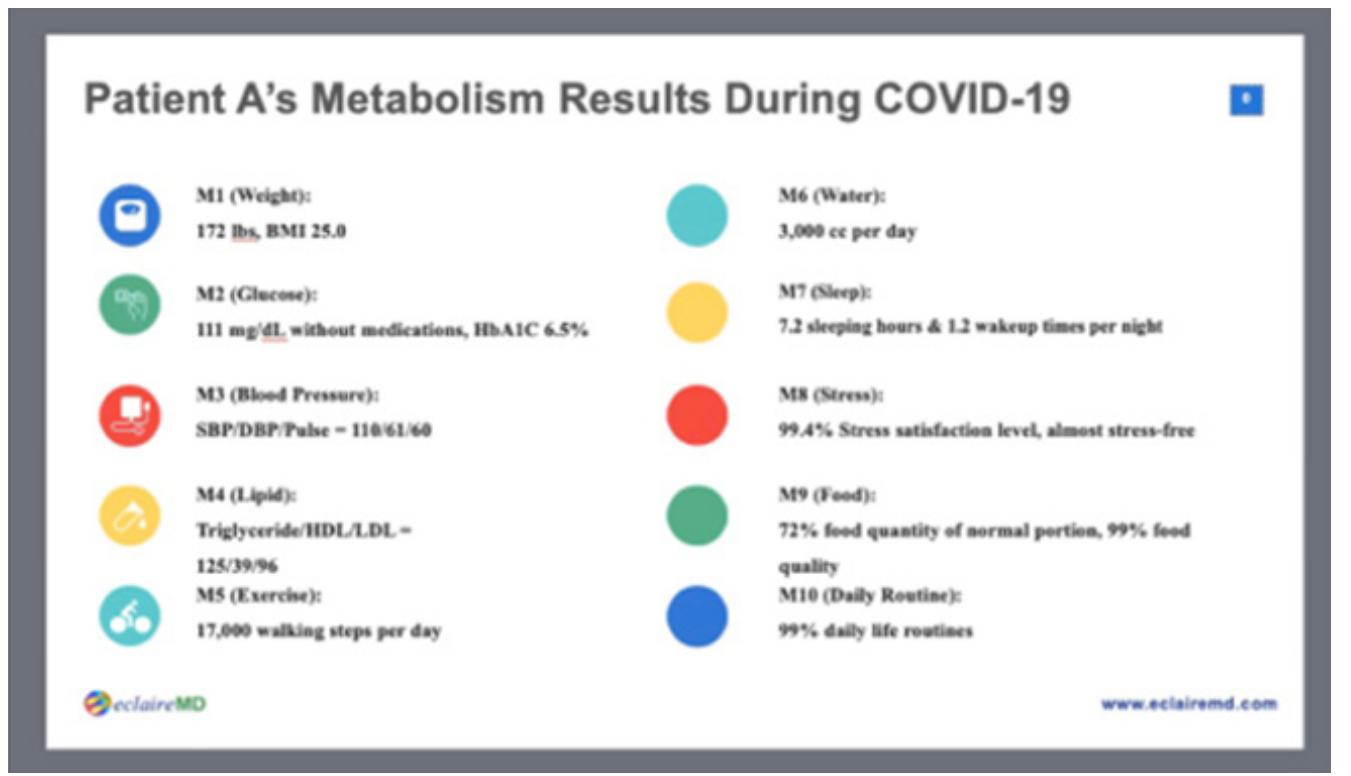

Figure 6 Patient A's Metabolism Results during COVID-19.

\section{Results}

\section{Epidemic information}

Figure 2 shows the author's own data analysis of COVID-19. He focuses on zones (a single nation or an area with multiple nations) having transparent information, such as the US, UK, and Europe. Within Zones 1, 2, and 3, including Europe, US, and UK, he found a confirmation percentage of $0.18 \%$ to $0.35 \%$ and a death rate of $5.8 \%$ to $10.1 \%$. With regard to this virus death percentage, most countries in the world have a similar death rate percentage of about $4 \%$ to $10 \%$. Two exceptionally well-controlled zones are: nations with dense populations with 591 people per square $\mathrm{km}$ (Zone 4) such as Taiwan, South Korea, and Singapore have $0.037 \%$ confirmation rate with a $0.92 \%$ death rate; and nations with sparse populations with 4 people per square km (Zone 5) such as Canada, Australia, and New Zealand have $0.1 \%$ confirmation rate with a $5.63 \%$ death rate. As a caveat, he could easily determine from his analysis which nations were hiding the truth about their confirmed case numbers or distorting the facts. For example, 3 particular nations' confirmed case percentages are extremely low, $0.003 \%, 0.006 \%$, and $0.012 \%$.

Once he developed his information of confirmation rate and death rate, he then tried to decipher the death rates associated with the senior age groups (Figure 3). Although different countries or cities have presented different death rate comparison results between the older age group ( $>70$ years old) versus the younger age group $(<40$ years old), the general idea is consistent. For a senior person, who has existing chronic diseases and history of complications, would have an extremely high death rate in the range of several tenth fold.

\section{Chronic disease}

The bold italic statements in following paragraphs are for COVID-19 period.

The following descriptions and Figures 4, 5 and 6 summarize Patient A's record of metabolic conditions for the last 6 to 8 years and during this COVID-19 period, 1/19/2020 - 5/4/2020.
M1 (weight): 176.7 lbs. (decreased from $198 \mathrm{lbs}$.) and $172 \mathrm{lbs}$. (BMI 25)

M2 (glucose): $124 \mathrm{mg} / \mathrm{dL}$ (decreased from $280 \mathrm{mg} / \mathrm{dL}$ ) and 111 $m g / d L$

M3 (blood pressure: SBP/ DBP): 111/68 (decreased from 139/96) and $110 / 61$

M4 (lipid: triglyceride/HDL/LDL/total cholesterols): 125/39/96/144, no lab-tested lipid data available due to virus

M5 (exercise): 15,800 walking steps (increased from $\sim 5,000$ steps / day) and 17,000 steps

M6 (drinking water): 2,837 cc / day (increased from $500 \mathrm{cc} /$ day) and 3,000 cc / day

M7 (sleep): 83\% satisfaction level; with 7 hours of sleep time and 1.5 wakeup times per night and 7.2 sleeping hours with 1.2 wake up times

M8 (stress): 95\% stress satisfaction level, almost lived a "stressfree" life and $99.4 \%$ stress satisfaction level

M9 (food \& meal): 68\% satisfaction level; with a daily food portion at $84 \%$ of previous food intake per meal and $95 \%$ satisfaction level of food and meal quality standard and $61 \%$ satisfaction level (the lower the better) with $72 \%$ food quantity (portion control for weight) with $99 \%$ food quality (very well-balanced nutritious food, the higher the better)

M10 (daily routine): $96 \%$ satisfaction level; have a very stabilized and regular daily normal routine life pattern and $99 \%$ high regularity of daily life routines

The author's overall metabolism index (MI) score has decreased from $102 \%$ prior to 2014 , dropped to below $60 \%$ after 2015 , and then down to $53 \%$ of MI (a lower MI means better metabolism conditions) during this COVID-19 period. 
In summary, three specific basic lifestyle guidelines have been followed by Patient A during this COVID-19 period:

1. Eat high protein foods and fresh vegetables and fruits; avoid red meat, processed food, starchy food, and high sugar-content food; and drink 2,000 to 3,000 $\mathrm{cc}$ water per day.

2. Walk 4 to 8 miles (9,000 to 18,000 steps or 6 to $11 \mathrm{~km})$ per day.

3. Sleep well, avoid stress (e.g. avoid absorbing too many virusrelated negative news or engaging in political arguments), and keep a normal life-routine (maintaining social-distance and avoiding large gatherings).

Patients B, C, and D have been advised to follow the similar lifestyle management guidelines; therefore, during this COVID-19 period, Patients $\mathrm{B}$ and $\mathrm{C}$ are able to keep their weight (no weight gain) and glucose (lower than $120 \mathrm{mg} / \mathrm{dL}$ ) under control without taking any diabetes medications. Patient $\mathrm{D}$ has just started her daily routines by following these guidelines. The author also believes that those efforts on metabolic maintenance and improvement would ultimately strengthen their overall immunity to protect themselves against the threats from COVID-19 virus. ${ }^{1-4}$

\section{Conclusion}

COVID-19 is more than 100 times worse than SARS in 2003, in terms of its spreading speed and scope, mortality rate, and emotional impact on the world population. People belonging to the "weaker" groups, such as the elderly, health problems (existing chronic diseases and history of complications), or psychological disorders, requiring additional attention, care, and assistance. Unfortunately, some ridiculous opinions have appeared and circulated on the internet that COVID-19 can wipe out these weak people in order to reduce the government's social welfare burden. Only an immoral person can think this way.

On the other hand, the author also saw positive signs of the human spirit when he read the following news:

1. An elderly patient in New York volunteered his hospital bed to rescue a younger patient.

2. 76,000 retired healthcare professionals went back to their old post to fight against the virus in New York City.

3. 25,000 retired healthcare professionals signed up on the first day to go back to their old post to fight against the virus in California.
4. Due to limited information, estimated thousands of healthcare professionals from all over China have already died in Wuhan to rescue COVID-19 patients.

This article is based on the author's own knowledge and specific practices to protect certain patients in References 3 and 4, over the past 106 days. He hopes his knowledge gained from the past 10-years of medical research work in the field of endocrinology and metabolism can help other chronic diseases patients to strengthen their metabolism and immunity to fight against COVID-19 effectively.

\section{Acknowledgments}

First and foremost, the author wishes to express his sincere appreciation to a very important person in his life, Professor Norman Jones at MIT and University of Liverpool. Not only did he give him the opportunity to study for his $\mathrm{PhD}$ at MIT, but he also trained him extensively on how to solve difficult problems and conduct any basic scientific research with a big vision, pure heart, and integrity.

The author would also like to thank Professor James Andrews at the University of Iowa. He helped and supported him tremendously when he first came to the United States. He believed in him and prepared him to build his solid engineering and computer science foundation. $\mathrm{He}$ is forever grateful to his mentor, who has a kind heart and guided him during his undergraduate and master's degree work at Iowa

\section{Conflicts of interest}

The authors declare have no conflict of interest about the publication of this paper.

\section{References}

1. Dr. Joshua AD, New York-presbyterian hospital, New York, NY., "COVID-19 at NYPH: What are the basics of the disease, symptoms and risk factors for non-critically Ill patients?".

2. Gerald $\mathrm{CH}$, eclaireMD foundation, USA; No. 235, "Linkage among metabolism, immune system, and various diseases using GH-Method: math-physical medicine (MPM)"

3. Gerald $\mathrm{CH}$, eclaireMD Foundation, USA; Using GH-Method: mathphysical medicine, mentality-personality modeling, and segmentation pattern analysis to compare two clinic cases about linkage between T2D patient's psychological behavior and physiological characteristics.

4. Gerald $\mathrm{CH}$, eclaireMD Foundation, USA; Progressive behavior modification for diabetes patients based on GH-MPM Method (mathphysical medicine and mentality-personality modeling) and psychological \& physiological linkage pattern analysis. 